\title{
Retórica del patriotismo e invención del enemigo exterior
}

\author{
Professor Miguel CATALÁN, PhD \\ Departamento de Ciencias Políticas, Ética y Sociología \\ Facultad de Derecho, Empresa y Ciencias Políticas \\ Universidad Cardenal Herrera-Ceu, Spain \\ E-mail: macianasensi@gmail.com
}

\begin{abstract}
After a brief historical introduction, this paper analyzes the rhetorical and persuasive elements of the patriotism of State in the sphere of political regimes of force that ruled some European Nations during the first third of 20th century. The paper ends with the analysis of the patriotism of State as persuasive element of propaganda in the United States after the Second World War.
\end{abstract}

Keywords: Patriotism; Nationalism; Propaganda; Terrorism; War. 
Al margen de su legítimo aspecto sentimental y político, en el que esta breve contribución no pretende entrar, el patriotismo no suele fallar como argumento político. Su eficacia demagógica, ligada a las emociones del miedo y al odio, supera la de cualquier otra proclama.

El reclamo del patriotismo amenazado por un avieso enemigo exterior es una patraña partidista o gubernamental tan reiterada que ha terminado cayendo en descrédito. El patriotismo fue durante la Antigüedad fue en primer lugar una emoción noble y en segundo un argumento (sofístico o no) utilizado con provecho para ciertas causas, pero ha experimentado una paulatina degradación entre los modernos. El uso del patriotismo como cortina de humo puede ejemplificarse en la expedición de castigo para apoderarse de Argel que emprendió en 1830 el monarca francés Carlos $\mathrm{X}$ cuando vio prosperar la oposición interna en su país. La acción militar tenía una sola finalidad, distraer la atención de sus súbditos de los asuntos internos (Bruun 1984, p. 46). Con cortinas de humo como esta y tantas otras, los términos "patriotismo" y "patriota" terminaron incurriendo en tal deshonra que hoy sólo se utilizan con prevención o ironía. Apenas algunos tribunos siguen aferrándose a su antiguo atractivo o pretenden sacarle nuevo brillo. Así el gobierno de Vichy, que entregó a Alemania no sólo el gobierno del país sino también a los judíos, comunistas y masones franceses para enviarlos a los campos de exterminio alemanes, sustituyó el lema revolucionario francés Liberté, egalité, fraternité por el de Travail, familia, patrie. El contrasentido saltaba a la vista ya en el momento de su acuñación.

En Inglaterra los letrados independientes zahieren el reclamo patriótico. Samuel Johnson definió en el s. XVIII el patriotismo como el último refugio de los sinvergüenzas. En el XIX, Macaulay escribió que el nombre de patriota, aplicado a quien constantemente hablaba pro domo sua de "la libertad de los ingleses", "la Carta Magna", "los derechos por los que nuestros padres habían derramado su sangre", etc., había llegado a usarse comúnmente como burla (Walpole 2009, p. 149). En el XX, G. B. Shaw describe el patriotismo de forma más empírica como la convicción de que el propio país es superior a todos los demás debido a que uno ha nacido en él. Tal simpleza es natural en tanto no evolucionada y resulta fácilmente explotada por el político y el demagogo. Cuando estos creen también sus falsedades chauvinistas, agregan el autoengaño a una emoción que les favorece.

Los regímenes más contumaces en esta patraña contra el extranjero sin nombre son, en general, los nacionalistas y autoritarios. Cuanto mayores son la efervescencia patriótica y la opresión política, más probable resulta el argumento de la gloria nacional frente a Estados vecinos. Y, sin embargo, también en las sociedades liberales o democráticas las minorías dirigentes suelen proclamarse más patrióticas que las mayorías dirigidas. El patriotismo estentóreo tiene siempre algo de impostado, y por tanto resulta compatible con la evasión de impuestos y otras 
conductas privadas antisociales. Como ocurre por antonomasia en la figura del Rey, los grandes patriotas unifican su sentimiento de dominio (de "posesión") patrimonializando la nación, haciéndola suya y, por ello, especialmente querida en tanto propiedad espiritual además de material.

El patriotismo de Estado se dirige contra las naciones exteriores, pero también contra aquellos grupos internos al Estado que presuntamente ponen en peligro su integridad. Es así como a principios del siglo XX, tras el magisterio nacional-católico de Menéndez Pelayo en 1880, se alza la bandera nacional de España contra cualquier enemigo del gobierno o la autoridad, hasta tal punto que cuando se quiera aplastar una revolución popular bastará con esgrimir la bandera nacional: "Sería la 'unidad de la patria' la que se predicara a los soldados llevados a Barcelona a reprimir la Semana Trágica, explicada como separatista" (Álvarez Junco 2016, p. 169), nos recuerda Álvarez-Junco. Claro que también se puede apelar al patriotismo si se quiere limitar la libertad de prensa:

En el siglo XX, serían las "ofensas a la Patria" las que sirvieran para la limitación de la libertad de expresión que representó la Ley de Jurisdicciones de 1906. [...] Sería la "salvación de la patria" la que solicitaron patrones catalanes y terratenientes andaluces ante el sindicalismo y el Trienio Bolchevique de 1919-1921. Y sería "España" la principal invocación de Primo de Rivera para justificar su pronunciamiento en 1923 (Álvarez Junco 2016).

Después, los círculos conservadores harán caer la II República tras un golpe de Estado fallido que llevará a la guerra civil con el argumento de que la facción levantada en armas representaba a la verdadera España. Antes de clamar: "ante todo, España, y, sobre España, Dios", José Calvo Sotelo se dirigía a los españoles, pero no a todos, sino sólo a aquellos "con solera tradicional, alma patriota y conciencia hispana” (Álvarez Junco 2016, p. 184). El argumento termina dirigiéndose a la meta final "ante todo, España", como si fuera la de todos los españoles, pero tras apartar a los malos de los buenos bajo la mirada de Dios; es decir, tras separar por adelantado la cizaña del trigo. Se da una tensión algorítmica entre España y los españoles en virtud de la cual España es la nuestra una vez despejamos la incógnita de los enemigos por vía de su muerte, exilio o asimilación. "Lejos de reconocer la intención nacionalizadora de las políticas republicanas", resume Álvarez Junco, "denunciaban en ellas lo opuesto: su diabólico proyecto de 'destruir' España, de desnaturalizar la esencia natural".

El patriotismo faccioso no figuraba sólo en la facción del ejército que impulsó el golpe de Estado. Luis Veres comenta los términos contrariados para definir la misma cosa según el bando que hiciera uso de la palabra: reaccionario frente a revolucionario, alzamiento nacional y cruzada frente a guerra, caídos frente a muertos (Veres 2006, p. 73). Pues, si bien en tono menor, también los propagandistas del bando 
republicano creían estar defendiendo a España de sus enemigos:

Los dos discursos enfrentados negaban que se estuviera librando una guerra entre españoles, denunciaban la presencia de alemanes, italianos o rusos en el otro bando, sin reconocer los aliados del propio, e invocaban el recuerdo del 2 de mayo de 1818. En los carteles propagandísticos de rojos y azules aparecían por igual Viriato, Agustina de Aragón o Luis Daoíz y Pedro Velarde. Los dos sostenían que se trataba de una nueva "guerra de la Independencia", de una defensa de España contra "invasores extranjeros" [...] para unos, los "rojos" eran extranjeros por ser ajenos a la tradición española: como para otros lo eran los fascistas por veranear en Biarritz, obtener apoyos de la banca internacional y someterse a una religión cuyo jerarca supremo vivía en Roma. Si en algo estaban de acuerdo los propagandistas de ambos bandos era en negar que se tratase de una guerra "civil", entre españoles (Álvarez Junco 2016, pp. 184-185).

José María Pemán define para el bando fascista la guerra civil como una "Nueva guerra de la Independencia, una nueva reconquista", y sostiene: "luchamos por los cuadros de Velázquez, por las comedias de Lope de Vega, por Don Quijote y el Escorial...". El diario $A B C$ controlado por el bando republicano daba parecidos argumentos. En un editorial del 25 de julio de 1936 titulado "Segunda Guerra de la Independencia" describe a los sublevados como "hombres nacidos en España pero que renuncian a todo nexo con la noble ideología patria" (Álvarez Junco 2016, p. 185). Ahora bien, el parecido entre los dos bandos no llega muy lejos; Álvarez Junco hace notar que el discurso republicano añadía a la defensa de España otros ideales como la libertad, la igualdad o el progreso, en tanto el discurso franquista se concentraba en el patriotismo; así lo confirma el nombre de "nacionales" que eligieron para definirse a sí mismos; a diferencia de ellos, el bando legítimo se definió como "republicano", más apegado a una forma de gobierno que a una nación, y, por tanto, más ajustado al partidismo de la guerra civil (Álvarez Junco 2016, p. 187).

A efectos políticos de forzar la polarización polémica entre ellos y nosotros, fue preciso arianizar también a los pueblos fascistas europeos, y de ahí los intentos del racismo italiano para convertir a los mediterráneos bajos y morenos en descendientes directos de los hiperbóreos altos y rubios. Revistas fascistas como La Difessa della razza llegaron a elaborar una teoría de la raza aquilina para convertir en ario al poeta nacional de nariz aguileña Dante Aliguieri (Eco 2013, p. 236).

La relación beneficiosa para los intereses del gobierno entre invención del enemigo exterior y pérdida de derechos civiles resulta ejemplar en la teoría nacionalsocialista. Goebbels propone en 1942 la censura completa en los medios del país bajo el principio de que las noticias adversas al régimen o a la nación se convertían en 
argumentos derrotistas frente al enemigo; poco más adelante establece que también en tiempos de paz la propaganda es cosa del Estado, y, por tanto, debe dejarse sólo en sus manos. El ministro de propaganda del III Reich se lamenta el 27 de enero de 1942 de que el gobierno ha sido demasiado blando con las noticias adversas, de forma que "la opinión en los círculos militares y gubernamentales de Berlín es esencialmente distinta de la que predomina en las grandes masas del pueblo. La causa de todo no es otra sino que esos círculos han recibido una gran cantidad de material derrotista, sin la contrapartida de informes objetivos sobre la verdadera situación. Es evidente que la gente que recibía este material necesitaba que se le dijese con frecuencia en qué forma debía interpretarlo. Esto se hace en nuestro Ministerio, pero no en los demás" (Goebbels 1967, p. 54). Más adelante escribe: "Considero absolutamente necesario que las agencias de noticias pertenezcan al Reich. La propaganda es una función del Estado [...] La política de noticias es un problema fundamental y estas cosas tienen que estar en manos del Reich y no del Partido" (Goebbels 1967, p. 75). El ministro de Propaganda se propone la tarea de vencer las dificultades para traspasar el poder del partido al Estado. La invención del enemigo exterior a ese partido único cada vez más identificado con el Estado se forjaría mediante la noción de "gran guerra racial", una fantasía que hacía aparecer frente a la nación alemana el vago conjunto de aquellas fuerzas que se le oponían como si estuvieran dominadas por el espíritu judío; la guerra racial, pues, enfrentaba a Alemania, un Estado fuertemente autoritario y centralista, dotado de finalidades concretas y un ejército disciplinado con ingentes medios materiales, contra una quimera pomposamente llamada "enemigo mundial" (Weltfeind).

Las autoridades nacionalsocialistas consiguieron que muchos alemanes creyeran estar siendo atacados por el enemigo mundial cuando un judío asesinó en noviembre de 1938 a un cargo de rango inferior del III Reich. Al identificar aquel asesinato con una declaración de guerra, las autoridades estaban señalando al judaísmo como el enemigo a batir. No importó que Herschel Grynszpan, de diecisiete años, hubiera disparado al diplomático Ernst vom Rath para vengarse de una situación familiar, la de sus padres y hermanos detenidos en la frontera de Polonia junto a otros diecisiete mil judíos polacos expulsados de Alemania. Cuando el secretario de la embajada alemana en París falleció el 9 de noviembre de 1938 a causa de las heridas, el aparato de propaganda del III Reich se apresuró a transformar los disparos de un adolescente desquiciado por la separación de su familia en una declaración de guerra. Robert Wistrich escribe:

La maquinaria de propaganda nazi denunció de inmediato la acción de Grynszpan como una "declaración de guerra" y parte de una conspiración judeomásonica a escala mundial. Ello desencadenaría por toda Alemania una orgía sin precedentes de violencia y terror feroces contra los judíos, que los propios nazis designarían con el eufemismo Reichkristallnach ("noche de los 
cristales rotos"), en alusión a los fragmentos de las ventanas de comercios judíos que resultaron destrozados por todo el país. A lo largo y ancho de Alemania, ardieron más de cuatrocientas sinagogas y se saquearon más de siete mil quinientos negocios y otras propiedades judías; por lo menos cien judíos fueron asesinados, muchos más resultaron heridos, y a treinta mil se los despachó de modo sumario a campos de concentración en los cuales sufrirían indecibles ultrajes (Wistrich 2002, pp. 113-114).

Las autoridades manejaron la versión de un estallido popular incontrolado contra los malvados judíos, pero la realidad resultó ser bastante menos espontánea. Joseph Goebbels, el ministro de Propaganda del III Reich, había concebido y puesto en marcha el pogromo al poco de confirmarse la muerte del vom Rath, pues ese mismo 9 de noviembre pronunció un discurso acusatorio en una cervecería muniquesa definiendo la bala mortal de un joven desesperado como una declaración de guerra:

Goebbels calificó la muerte del diplomático como el primer disparo de una nueva guerra entre los alemanes y los judíos. Sus diarios revelan que Hitler no sólo estuvo informado de todos y cada uno de los pasos que se dieron, sino que también manifestó explícitamente su deseo de hacer pagar a los judíos el daño cometido y expropiar sus negocios. [...] La Kristallnacht fue la exhibición pública de antisemitismo más violenta que se había visto desde las cruzadas [...] La escala y la impunidad de la violencia habían estigmatizado a los judíos, todavía más que antes, como un pueblo paria y no deseado, al cual se podía humillar a voluntad y que quedaba fuera del común de la sociedad y del universo de las obligaciones morales [...] veinte años después de la rendición alemana, el pogromo contra los judíos era un medio de preparar psicológicamente a la nación alemana para una nueva guerra europea (Wistrich 2002, p. 121).

De la inexistente gran guerra racial alemana contra los judíos pasemos a la impostada guerra fría entre estadounidense y soviéticos. Desde el punto de vista soviético, la cúpula del Partido Comunista logró establecer entre sus ciudadanos un sistema represivo y dictatorial aprovechando la inercia de la "mentalidad de guerra civil" de Lenin y luego de Stalin y la presunta necesidad de mantener la alerta ciudadana ante los enemigos exteriores e interiores. "El sistema soviético había necesitado el fantasma de un enemigo exterior permanente", escribe Henry Kissinger evocando las causas del derrumbe soviético en los años ochenta, "para justificar los sufrimientos que imponía a su pueblo y para mantener las fuerzas armadas y el aparato de seguridad que eran esenciales para su gobierno" (Kissinger 1998, p. 1194). Fue justamente cuando bajo Gorbachov se pasó de la mera coexistencia con Estados Unidos a la interdependencia (1986, XXVII Congreso del 
Partido Comunista) cuando desapareció toda coartada moral para la represión soviética interna (Idem). Dotado de una superioridad tecnológica y militar siempre creciente a partir de los años cincuenta, lo mismo puede decirse aún en mayor grado de Estados Unidos. La aceptación popular en aquel país de la formación del complejo militar-industrial en los años 50 del siglo XX no habría sido posible sin la Segunda Guerra Mundial; el posterior concurso de la industria del espectáculo y de los medios de comunicación al servicio de las autoridades políticas y militares ha fomentado hasta el día de hoy entre los estadounidenses el miedo a amenazas exageradas o inventadas a fin de justificar los descomunales gastos de defensa. Las sucesivas guerras y operaciones encubiertas del imperialismo económico estadounidense proceden del ingente presupuesto militar, cuyas dimensiones casi apocalípticas debe justificarse una y otra vez ante el pueblo y las cámaras de representantes. Sociólogos como Charles Wright Mills ya advirtieron en los años cincuenta al presidente Eisenhower que se estaba formando una formidable sinergia entre la industria y el ejército a fin de consumir la mayor parte posible del presupuesto federal con la excusa de que el país seguía en estado de guerra aunque hubiese cesado el fuego tras las bombas atómicas en Japón. “Su preocupación [de Mills] era que los fabricantes de armas y el Ejército estadounidense tenían intereses comunes que iban en contra del proceso político" (Altheide 2002, p. 126). La industria armamentística aprovechó el cultivado terror ciudadano durante la Guerra Fría para convertirse en el lobby más poderoso en torno a un departamento de Defensa que iba a impulsar por su causa decisiones políticas favorables al despliegue militar de Estados Unidos en todo el mundo. Como explica David Altheide, la propaganda ha terminado por fundirse con el formato del entretenimiento al unir noticias y espectáculo militar en las grandes cadenas televisivas. El mundo del cine y los medios de comunicación audiovisuales se intercambian favores económicos y logísticos con el Ejército al emitir aquellas noticias y producir aquellas películas que priman el apoyo al esfuerzo militar (Altheide 2002, pp. 126-127). Este refuerzo mutuo entre los medios de comunicación y entretenimiento y las relaciones públicas del Ejército a través de la propaganda más o menos encubierta comenzó a gran escala en la Primera Guerra Mundial con el desarrollo del Comité de Información Pública (Altheide 2002, p. 127).

Los mitos imperiales tienden a complementarse. La agresiva política exterior estadounidense posterior a la Segunda Guerra Mundial se ha valido de una invención diplomática, la de la "política de contención". Según este último rentable embeleco, Estados Unidos jamás tuvo interés en crear un imperio, sino que fue en realidad el imperialismo comunista soviético el que le obligó a salir de su aislacionismo vocacional para contener una agresión totalitaria al mundo democrático que iba a terminar llegando a América de no tomarse medidas. En el análisis de Heinz Dieterich, sin embargo, la doctrina de la contención se basaba en supuestos 
falsos. En realidad, la Unión Soviética había perdido por efecto de la invasión nacionalsocialista la mitad de su potencia económica, incluyendo la industria pesada de la cuenca del Donets y los centros agrícolas de Ucrania y Bielorrusia. Veinte millones de ciudadanos soviéticos habían perdido sus vidas y otros veinticinco millones, sus casas. A diferencia de la URSS, EE. UU. pudo desarrollar rápidamente su capacidad productiva y dejó atrás la guerra como la potencia económica y militar más fuerte del mundo; su número de parados descendió de nueve millones en 1940 a sólo un millón en 1945 y la producción laboral aumentó de 1939 a 1944 en un $25 \%$. El agudo contraste entre las dos potencias afectaba también al plano militar: en realidad, era la URSS la que se encontraba rodeada por un cinturón de bases militares y puestos de escucha del imperio estadounidense. Al acabar la guerra y en los años subsiguientes, la URSS no disponía de fuerzas estratégicas navales ni aéreas dignas de mención. La diferencia en tecnología de armamentos era enorme, además de que EE. UU. poseía el monopolio de las armas nucleares. “Bajo esas condiciones", explica Dieterich, "cualquier política expansionista de la URSS habría sido suicida y los planificadores occidentales eran perfectamente conscientes de ello. Los documentos secretos de aquellos años, reclasificados hoy en día, demuestran que los planificadores norteamericanos no contaban con un ataque de la URSS. Los expertos de los servicios secretos estadounidenses calcularon que la URSS tardaría al menos quince años en compensar las pérdidas humanas e industriales" (Dieterich, 1996, pp. 89-90). Sin embargo, la doctrina de la contención se formula apenas terminada la Segunda Guerra Mundial, en julio de 1947. George Frost Kennan, el politólogo que defendió la naturaleza expansionista de la URSS y la necesidad estratégica de contenerla, aconsejó enfrentarse a los soviéticos "con una fuerza contraria inalterable en todos los sitios donde ellos demuestren la intención de acercarse a los intereses de un mundo pacífico y estable". En ese mismo artículo Kennan llegó, sin embargo a la conclusión de que "Rusia", comparada con Occidente, "sería con diferencia la parte más débil". Cuarenta años después se reafirmaría en esta última estimación: "De ninguna de las maneras la URSS me pareció entonces un peligro militar para este país [...] El nivel de destrucción física había sido impresionante [...] Era en ese momento impensable intentar la removilización de las fuerzas armadas para otra guerra, y, particularmente para otra guerra de agresión. Rusia entonces no tenía ninguna Marina que mereciera ese nombre y virtualmente ninguna fuerza aérea estratégica"(Dieterich, 1996, p. 90).

La doctrina de la contención estuvo basada en una útil exageración sobre la capacidad expansionista soviética y funcionó como un mito conveniente que permitía dar cobertura a los intereses estadounidenses en todo el mundo. En 1961, el coronel Virgil Ney explicó que la palabra "contención" aplicada al enemigo comunista no debía tomarse al pie de la letra: "No importa si este o aquel movimiento de liberación está unido al comunismo. En la medida en que [...] intenten despla- 
zar a las fuerzas occidentales de una posición de fuerza en la periferia europea o asiática, sus metas estratégicas son paralelas a las del bloque chino soviético" (Dieterich, 1996, p. 91). Así pues, "contención" significaba en realidad lo contrario de contención; a saber, cualquier política que reforzara la posición hegemónica estadounidense en cualquier lugar de la periferia europea o asiática.

A su vez, el concepto embustero de "Guerra contra el terror" del siglo XXI tiene sus antecedentes ya bajo el mandato de Ronald Reagan. William Casey, director de la CIA, tomó entonces al pie de la letra las fantasías conspiratorias del ideólogo neoconservador Michael Ledeen para declarar a la URSS el Mal personificado que se ocultaba tras todos los movimientos insurgentes del mundo. Ledeen defendía las tesis del libro de Claire Sterling La red del terror (Terror Network, 1981). Sterling alimentó en sus páginas la pavorosa fantasía de que todos los grupos terroristas del mundo estaban coordinados por la URSS; del IRA a Baader Meinhoff y de ETA a las Brigadas Rojas, no se trataba de grupos nacionalistas o de clase que se rebelaban contra los Estados respectivos, sino de agrupaciones instrumentalizadas y financiadas por Moscú. Casey, Ledeen y Sterling testificaron como miembros del Subcomité del Senado para la Seguridad y el Terrorismo que la URSS financiaba y entrenaba a una gran variedad de grupos terroristas. Pese a todas las críticas, incluyendo la de altos cargos de la propia CIA que desautorizaban la idea de la conspiración mundial comunista, Casey se convirtió en el subordinado con más influencia en la voluntad del presidente Reagan. Este firmó en 1983 bajo su consejo unas iniciativas destinadas a cambiar la política exterior; a partir de ese año EE. UU. financiaría abiertamente guerras en todo el mundo para detener a la URSS, también en Afganistán. La misma noción de "guerra preventiva" puede rastrearse en discursos del decenio Reagan; así, su secretario de Estado George Schultz explicó en un mitin de 1984, poco antes de las elecciones presidenciales de ese año: "Debemos alcanzar un consenso en este país de que nuestras respuestas deben ir más allá de la defensa pasiva y considerar medios de prevención activa, anticipación y represalia [...] Necesitamos la flexibilidad de responder a los ataques terroristas con variedad de métodos, en momentos y lugares de nuestra propia elección" (Toaldo 2012, p. 2).

El hundimiento del comunismo como enemigo único fue una mala noticia para los beneficiarios del sistema de explotación del miedo estadounidense, pues desinflaba el globo del enemigo único que permitía justificar los descomunales presupuestos de defensa y el descuido de las partidas dedicadas a servicios sociales. Había que buscarle un sustituto, y pronto se llenó el hueco configurando la amenaza yihadista. El propio Michael Ledeen arguyó en The War Against the Terror (2003) que la "red unificada del terror" sobrevivió al hundimiento de su principal, patrocinador, la URSS, gracias al yihadismo. Alguien debía tomar el testigo de la confabulación única contra Estados Unidos, aunque el yihadismo careciera de la 
estructura centralizada de la antigua URSS. Del mismo modo que los ideólogos del III Reich se inventaron una "guerra racial" entre el mundo germanoario y el semítico sin tener un enemigo organizado judío, ni mucho menos un Estado judío, al que enfrentarse, sino sólo con el fin de reorganizar Europa desde criterios étnicos (Wistrich 2002, p. 127), así los ideólogos de EE. UU. inventaron una "guerra contra el terror" sin tener un enemigo organizado terrorista, ni mucho menos un Estado terrorista, al que enfrentarse. Las posteriores atrocidades cometidas por el Estado Islámico serían una consecuencia, no la causa, de la Guerra contra el Terror. Descrita por la Civilización que pone nombres a las cosas, la secuencia fue como sigue. En primer lugar, los tártaros al otro lado del desierto tenían que estar agazapados a la espera de la ocasión propicia, y era cuestión de tiempo que asaltaran la fortaleza. Sólo que en esta ocasión la defensa de la civilización no fue tímidamente pasiva, sino que salió de la fortaleza tomando una prevención activa para "atacar en momentos y lugares de nuestra propia elección". En respuesta y consecuencia, los tártaros atacaran en lo que estos denominaban arteramente una respuesta al ataque llevado a cabo por la civilización.

El Manifest Destiny de Estados Unidos como país elegido por Dios para llevar el bien a todo el mundo no tardó, pues, en crear tras la caída de la URSS un nuevo enemigo del conglomerado inestable de países amigos hábilmente presentado con el ecuménico nombre de "comunidad internacional". Se precisaba un enemigo único, a ser posible menos efímero que el comunismo. $Y$, en efecto, así como no hay tregua interior en la "guerra contra el crimen", no habrá paz externa contra el yihadismo, sino sólo tregua o "estado de descanso". Con tal locución definía Thomas Hobbes los periodos entre guerra y guerra: un estado de descanso marcado por la incertidumbre y el anhelo de seguridad a la espera de nuevas hostilidades. El yihadismo sería ese enemigo eviterno para luchar contra el cual el país y el mundo necesitan seguir siendo regidos por un sistema económico acaparador dotado de un inmenso presupuesto militar con sus grandes beneficios anejos.

En conclusión, el yihadismo que exige una "guerra contra el terror" prestaría el mismo servicio que rindió el comunismo durante medio siglo. Felipe Sahagún ha vinculado la instrumentación del peligro comunista con la del subsecuente del peligro terrorista al señalar que los periodistas occidentales han repetido durante años la mentira de la amenaza o superioridad militar soviética a lo largo de la Guerra Fría, necesaria para justificar unos presupuestos militares anuales difícilmente defendibles de otra forma ante los ciudadanos (Sahagún 2004, p. 82).

\section{Bibliografía}

1. Altheide, David L. (2002). Creating Fear, Nueva York: Walter de Gruyter.

2. Álvarez Junco, José (2016). Dioses útiles. Naciones y nacionalismos, Barcelona: Galaxia Gutenberg. 
3. Bruun, Geoffrey (1984). La Europa del siglo XIX, México, D. F.: Fondo de Cultura Económica.

4. Dieterich, Heinz (1996). "Una ironía de la historia”, en Noam Chomsky y Heinz Dieterich, Los Vencedores, Madrid: Voz de los sin voz, pp. 55-109.

5. Eco, Umberto (2013). Historia de las tierras y lugares legendarios, Madrid: Lumen.

6. Goebbels, Joseph (1967). Diario, Barcelona: Ediciones G. P.

7. Toaldo, Mattia (2012). "The Reagan Administration and the Origins of the War on Terror: Lebanon and Libya as Case Studies", New Middle Eastern Studies, II, pp. 1-17.

8. Kissinger, Henry (1998). Diplomacia, Barcelona: Ediciones B-

9. Sahagún, Felipe (2004). "La propaganda en la guerra de Iraq", en Catalán, Miguel, y Veres, Luis (coords.), Estrategias de la desinformación, Valencia: Biblioteca Valenciana, pp. 81-102.

10. Veres, Luis (2006). La retórica del terror, Madrid: Ediciones de la Torre.

11. Walpole, Horace (2009), reseña a Letters to Mann, cit. en el prólogo a Samuel Johnson Escritos políticos, Madrid: Katz.

12. Wistrich, Robert (2002). Hitler y el Holocausto, Barcelona: Mondadori. 